\title{
¿ES LA DOSIS DE INDUCCIÓN CON SEVOFLUORANO UN FACTOR DETERMINANTE DE LA OCURRENCIA DE AGITACIÓN POST-ANESTÉSICA EN NIÑOS?
}

Nicolás Aeschlimann D ${ }^{1}$, Pamela Chomali, Laura Gebauer ${ }^{1}$, Augusto Rolle ${ }^{1}$, Alejandro González ${ }^{1}$, Mauricio Ibacache ${ }^{1}$

1 División de Anestesiología, Facultad de Medicina, Pontificia Universidad Católica de Chile.

Introducción: La inducción anestésica con sevofluorano sería un factor causante de agitación post-anestésica (APA) en pacientes pediátricos. Además, en concentraciones mayores de 6\% produciría actividad epileptiforme, la cual podría estar relacionada a APA. En teoría, inducción con sevofluorano en dosis menores a $6 \%$ podría disminuir la ocurrencia de APA en niños.

Objetivo General: Comparar la incidencia de APA en niños anestesiados con dosis de sevofluorano de $5 \%$ y de $8 \%$.

Material y Métodos: Ensayo clínico aleatorizado, doble ciego, en pacientes de 2-7 años, ASA I-II, sometidos a cirugía de circuncisión o herniorrafia inguinal con anestesia general y bloqueo caudal. Se excluyeron pacientes con contraindicación para gases halogenados o bloqueo caudal, ASA III o mayor, uso de coadyuvantes o de anestesia total intravenosa. Se registraron: variables demográficas; signos vitales, profundidad anestésica por BIS y respuesta motora postvía venosa, post-instalación de mascara laríngea, post-bloqueo caudal, post-incisión quirúrgica y al finalizar la cirugía; tiempos de anestesia, de cirugía y de estadía en recuperación; APA al despertar en pabellón con Escala Agitación PostAnestésica Pediátrica (PAED). En recuperación se registró, cada 15 minutos durante 2 horas: APA (PAED); dolor con escala CHIPPS o EVA; náuseas y vómitos postoperatorios. Análisis estadístico: t-test para muestras independientes $\mathrm{o}$
Mann-Whitney según corresponda para variables intervalares; test Chi-cuadrado o Fisher según corresponda, para asociación entre variables categóricas. Significancia estadística: $\mathrm{p}<0,05$.

Resultados: Se reclutaron 33 pacientes: 16 recibieron Sevofluorano 5\% y 17 recibieron sevofluorano $8 \%$ (48,5 y 51,5\% respectivamente). No hubo diferencias significativas entre los grupos en las variables demográficas, signos vitales, tiempo de anestesia, tiempo quirúrgico o tiempo en recuperación. No hubo diferencias entre los grupos en los valores de BIS en ninguno de los momentos evaluados $(\mathrm{p}>0,21)$. Tampoco hubo diferencias significativas en la respuesta motora en los momentos evaluados. La incidencia de APA al despertar fue $31,3 \%$ en el grupo sevofluorano $5 \%$ y $35,3 \%$ en sevofluorano $8 \%(p=0,8)$. La incidencia de APA en la unidad de recuperación fue $43,8 \%$ y $41,2 \%$ para los grupos sevofluorano $5 \%$ y $8 \%$ respectivamente $(p>0,38)$. Tampoco hubo diferencias en la incidencia de náuseas y vómitos postoperatorios $(\mathrm{p}=0,1)$.

Conclusiones: Las dosis de sevofluorano utilizadas permitieron realizar una adecuada inducción anestésica, en términos de profundidad anestésica y respuesta a los estímulos. Sin embargo, estas dosis no fueron un factor determinante en la ocurrencia de APA en nuestros pacientes. La incidencia de APA encontradas son similares a las reportadas en la literatura. 